\title{
UNDERLYING CAUSES OF SEXUAL HARASSMENT IN INSTITUTIONS OF HIGHER LEARNING IN UGANDA: RESPONSES FROM KYAMBOGO UNIVERSITY
}

\author{
H. Kebirungi \\ Development Studies \\ Kyambogo University \\ Kampala, Uganda \\ https://orcid.org/0000-0002-3500-0524
}

\section{ABSTRACT}

This study used the social exchange theory and sexuality to investigate the underlying causes of sexual harassment in Institutions of Higher Learning in Uganda, with responses from Kyambogo University (KyU). Data were collected from internal and external stakeholder consultative meetings and workshops and the literature review. External participants were purposively selected from representatives of the Ministry of Education and Sports, public universities and non-governmental organizations, while internal participants were drawn from student leaders and university managers. Three meetings and two workshops were conducted with 390 participants (214 females and 179 males). The study provides evidence of sexual harassment (SH) at $\mathrm{KyU}$. The underlying causes were limited awareness of SH among university stakeholders, students' background, poverty and a culture of silence. There is need to embark on a programme of building a safe and positive learning environment, supported by continuous sensitization and informed by an in-depth multi-stakeholder study on the status of $\mathrm{SH}$ at the University.

Key words: Kyambogo University, institutions of higher learning, sexual harassment, Uganda

\section{INTRODUCTION}

Sexual harassment (SH) in institutions of higher learning (IHL) has become a worldwide pandemic (Bondestam and Lundqvist 2020, 397; Ondicho, Kombo, and Njuguna 2019, 44). According to Murray, Nguyen and Cohen $(2014,322) \mathrm{SH}$ is the involvement of another person in a sexual activity that he or she does not fully comprehend, and is unable to give informed consent. SH violates the laws or social values of society (Ministry of Education, Science, Technology and Sports (MOESTS) 2015-2020, 8-10). SH manifests itself in several ways, such as unwelcome sexual advances, requests for sexual favours and physical harassment of a sexual nature (Kirkner, Lorenz, and Mazar 2020, 2). Other forms of SH are making sexual comments, touching or fondling a person for sexual gratification, and being forced to look at sexual organs, images or pornography (MOESTS, 2015-2020, 3).

In Uganda, 77.7 per cent and 82 per cent of primary school and secondary school learners, 
respectively, experience SH while at school. Eight percent of female students under 18 (the legal age of consent) have been exposed to defilement (sexual intercourse), 24 per cent of female students over 18 have been talked to in a sexual way, 18 per cent have received a marriage proposal, 25 per cent have been stroked in a sexual manner and 29 per cent have been exposed to electronic sexual materials (MOESTS 2012, 3). Female learners suffer from SH twice as much more than their male counterparts (Magaji et al. 2019, 40). Gillander and Stein $(2019,992)$ and Sundaram and Jackson $(2018,3)$ established that SH was due to formalization, covering up, under-reporting and a culture of silence imposed on survivors. Aguilar and Baek stated that in academic departments, more students in life and physical sciences than in other disciplines conceal their experience of SH from faculty academics, because of the conspiracy at institutional and departmental level that is aimed at under-reporting SH (Aguilar and Baek $2020,1)$.

The effects of SH are grave, as it impedes the victim's education, resulting in poor academic performance and continuous absenteeism, and lowers female students' self-esteem (Dogar 2021, 1192), all of which affects their health, with them experiencing mental, economic and physical frustration (Bondestam and Lundqvist 2020, 405; Kirkner et al. 2020, 2). In Uganda, SH accounts for high a level of teenage pregnancy, HIV and AIDS and other sexually transmitted infections (UNICEF 2015, 20-21).

In 2012, the Government of Uganda, through the Ministry of Education and Sports (MoES), with support from UNICEF, undertook a study on violence against children in Ugandan primary and secondary schools. The study resulted in the establishment of an intersectoral committee on violence against children in schools (ISC VACiS), the development of reporting, tracking, referral and response (RTRR) guidelines on VACiS, and the development and on-going implementation of the national strategic plan on violence against children in schools (NSP VACiS) 2015-2020.

Despite the aforementioned studies, efforts to reduce SH in schools by Uganda's MOES have all focused-on SH in primary and secondary schools, where response mechanisms and policy guidelines have been developed and are now being disseminated and implemented. There is limited information on the underlying causes of SH in IHL in Uganda, and so this study will contribute to the body of knowledge by investigating the underlying causes of SH in IHL in Uganda, with responses from Kymbogo University (KyU).

\section{THEORETICAL PERSPECTIVE}

This article used the social exchange theory and sexuality (Sprecher 1998) to investigate the underlying causes of $\mathrm{SH}$ at $\mathrm{KyU}$, because its main tenet provides an understanding of how a 
sexual relationship is negotiated by two people, which partner has more influence on what sexual activities they do together and on sexual satisfaction, and the likelihood that one or both partners will engage in sexual activity outside the relationship. The theory applies the three social exchange models with particular relevance to sexuality, namely, the equity theory (e.g., Walster, Walster, and Berscheid 1978, 35), the Investment Model (Rusbult 1980; 1983, 101) and the Interpersonal Model of Sexual Satisfaction (Lawrence and Byers 1995, 267).

The main focus of the social exchange theory is on the exchange of resources (material or symbolic) between people that takes the form of rewards, costs, sexual favours and reciprocity. The strength of this theory is that it can be used in both the private and public spheres to interrogate the types of sexual transactional activities that take place, especially in IHL, and to question the exchange values involved in a sexual transaction. For example, the social exchange theory states that the existence of power determines which partner (student, lecturer, administrative staff member, sugar daddy or sugar mummy) has more influence on what sexual activities they do together, but it does not discuss other sexual behaviours that do not have a positive exchange value, which can be harmful to an individual and lead to revenge. Furthermore, the social exchange theory and sexuality does not consider the diversity of cultures, whereby some cultures knowingly or unknowingly promote $\mathrm{SH}$ and violence. However, it is used to question how the KyU community perceives $\mathrm{SH}$, students' poverty and their exposure to $\mathrm{SH}$, how lecturers use their power and influence to sexually harass students or students to sexually harass other students, and how the culture of silence promotes SH.

\section{METHOD}

\section{Data collection}

Qualitative data were collected through meetings and workshops with 390 participants (214 females and 179 males). Three meetings were conducted with 60 participants (34 females and 26 males). The first brainstorming meeting involved 24 participants (16 females and 8 males) drawn from KyU Managers (Vice Chancellor and Deputy Vice Chancellors, Human Resources, Security, Health services, Legal office, Dean of students, Guidance and Counselling). The Assistant Director of Gender Mainstreaming at $\mathrm{KyU}$ chaired the meeting and asked the participants to broadly discuss the underlying causes of SH in IHL. The major themes captured comprised limited awareness of SH, students' background of poverty and a culture of silence. The meeting lasted three hours. The second meeting was conducted with 20 student leaders (10 females and 10 males). The third meeting involved University lecturers, with 16 participants (8 females and 8 males). 
Workshop participants were drawn from internal and external stakeholders, comprising teaching and non-teaching staff, students, Ministry of Education and Sports officials and NGOs. The workshops were organised as pre-event activities to mark International Women's Day in March 2020. The themes of the workshops were derived from the broader international women's day theme, "I Am Generation Equality: Realizing Women's Rights". The theme of the first workshop, "Consent and healthy relationships", attracted 67 participants (46 females and 21 males). The second workshop with the theme of "Gender-based violence in IHL" attracted 263 participants (134 females and 129 males). Additional data were obtained from the literature review. The study was conducted from August, 2018 to March, 2020.

\section{Data analysis}

The data were subject to qualitative content analysis. All descriptive data were captured verbatim. The analysis used some of Harding and Whitehead's (2013, 143 procedures for qualitative analysis, namely: 1) reading the notes several times and noting the themes that emerged; 2) placing the data with similar themes into categories, such as limited awareness of SH, students' background, poverty and a culture of silence; and 3) interpreting the meaning and reporting the findings on the underlying causes of SH in IHL in the results section.

\section{ETHICS}

Permission to conduct this study was granted by the KyU Vice Chancellor, who also wrote letters of invitation to the meetings and workshops that were organised. The process and purpose of the research were explained to the participants. Only those who consented to participate in the study registered before the start of the study. Participants' responses were kept anonymous and confidential.

\section{RESULTS}

Findings on the underlying causes of $\mathrm{SH}$, comprising the themes of limited awareness of $\mathrm{SH}$, poverty among students, lecturers using power and influence to harass students sexually, students' SH of other students, and the culture of silence among students and management are presented below.

\section{Limited awareness of SH}

The participants were not aware that SH was an infraction of a person's human rights and that it has multiple negative consequences. They were also ignorant that unwelcome sexual attention like body touching, fondling, kissing, hugging, staring, or telling lewd jokes without their 
consent were forms of SH, as stated below.

"This concept of SH is being taken at a higher level. We are used to hugging males and females as a form of greeting and you don't need to ask for permission to do this. To us who come from the western part of Uganda hugging someone signifies happiness and respect for those we greet, and is not disrespectful. I think you are just importing European values into our culture. Verbal comments do not harm. Let me tell you, if for example you do not joke with a woman that she is looking good, or if you do not touch her breasts, waist or thighs, she will think that you are a coward or that you have no interest in her and she may hate you forever. As long as the female is aged over 18, then one is safe. I don't need permission to touch her body. I will take hold of her hand and ask her to accompany me to my room and if she accepts, the walls will tell it all. I will satisfy myself sexually and, to avoid commitment, I will immediately tell her to go away. I have not beaten her; we have both satisfied our sexual desires and you tell me that is sexual harassment?"

In a meeting a male student leader, 2018 stated:

"The question here is why should a female student agree to go out with me till late in the night or come to visit me in my room at night? If the female students don't protect themselves, who am I to talk about SH, something I don't even know about? A female student will give excuses like you know my roommate has gone away with the key and I have to wait for her to return ... cooking stories just to buy time until it gets too late for her to leave your room. Female students on the campus are the ones leading us into temptation. After firing (having intercourse with her) she will go, period! She turns herself into a wife by coming every day, and if you have friends, you invite them to come and enjoy a free service. When you all dump her that is when she starts quarrelling and telling people that this boy is a rapist, etc. If you want to teach us about the dangers of $\mathrm{SH}$, tell our sisters to stop tempting us."

In relation to the social exchange theory there is evidence that both male and female students negotiate and influence sexual activities. Although the male's actions in sexual relations sometimes become forceful, the female will play the diplomatic card of being locked out by her roommates and seeking refuge in the boy's room, which is when the male student gets lured into sexual activity. The University management and student leaders pointed out that limited awareness of SH was attributed to societal acceptance and normalization of SH in communities including universities, where victims do not report cases of SH for fear of being branded sex pests. It also came out clearly in the meeting that institutional systems tend to protect the perpetrators of $\mathrm{SH}$ in order to guard them from the shame and embarrassment of their family and University community finding out about their behaviour. A discussion with male student leaders confirmed the above as stated below:

"Students' background and moral decadence have contributed to SH on campus. Some students join University when they are already sexually active. Students from poor or rural families are 
more sexually active than those from well-to-do or urban families. Poor housing in the rural setting, where rooms for adults are not separated from those of children, contributes to sexual harassment. The fact that most families live in 'huts' that are smaller than a single room without compartments means that children grow up knowing that their parents practise sex. Therefore, students start practising incest with their siblings and everyone in the home is silent about it. Unsupervised outdoor activities like fetching water, gardening, collecting firewood and grazing animals in the rural setting expose young girls and boys to sexual harassment at an early age, causing them to transmit immoral and sexual behaviour and practices from their families and communities to educational institutions, including this University"

A female student in a discussion at a meeting in $\mathrm{KyU}$ in 2019 had this to say:

"The main perpetrators of SH at community level are our close relatives, like brothers, sisters, uncles or aunties and cousins, or housemaids and neighbours. My uncle defiled me several times when I was still young. Otherwise, if it not been for the delayed monthly menstruation periods which came when I was 16 years old, I would have dropped out of school and had 3 children by now. Sadly, I'm just realising it now that it was SH because, although my parents knew about it, they were not bothered at all because he was the one paying my school fees."

The situation presented above was amplified by the collapse of traditional social systems that provided the basis for collective responsibility for ensuring the growth, safety and security of children in communities and educational settings. Based on the social exchange theory, the payment of fees for the learner was a typical sexual transaction agreed upon by the family of the female student.

\section{Poverty among students}

Poverty was mentioned during workshop discussions as another factor that increased male and female students' vulnerability to SH. It was revealed that both male and female students engaged in transactional sex in compensation for fees, upkeep or good examination marks with members of both the internal and external university community as stated by a University Administrator.

"Some parents are too poor to make a lump sum payment for tuition fees to the University but prefer to pay in instalments. However, they are sometimes unable to pay all the tuition fees before students register for examinations as required by the University policy, which causes those that have not paid a lot of frustration. Some students run to their lecturers or administrative staff requesting them to stand surety so that the University will allow them take the examination. It is university policy to recover such money from the guarantor's salary if the student fails to pay. Some male lecturers and administrative staff have taken advantage of this frustration to sexually harass female students. Poverty also forces male and female students to engage in transactional and survival sexual relationships by getting married to older women or men (sugar mummies or sugar daddies) with the hope of improved maintenance." 
The above statement was corroborated by student leaders:

"Some male or female students prostitute themselves not because they come from a deprived background but because they want a higher standard of living. The need to show off and look classy with a new phone, clothing and hairstyle, and to go on routine outings to bars, are some of the reasons why students are sexually exploited. Some parents also intentionally marry off their daughters to wealthy men in exchange for tuition fees for their education. A friend of mine told me that her parents left the responsibility for her upkeep with a married man from her village currently working and residing in Kampala. Every Tuesday and Thursday this girl goes and sleeps there. When I asked her whether she was safe, she told me that she does not care as long as the sexual relationship results in a University degree. She told me that it is the man paying her tuition fees and that her parents are aware of this."

From the social exchange theory point of view, perpetrators of SH use poverty as a negotiating economic power to abuse students' rights by harassing them sexually. On the other hand, parents sacrifice their children to sexual activities in exchange for their academic achievement without questioning the effect of such activities on the health of their children, especially girls.

\title{
Lecturers use power and influence to harass students sexually
}

Another form of sexual harassment reported at $\mathrm{KyU}$ was that of lecturers who sexually harass students, as revealed in the meeting with student leaders.

\begin{abstract}
"Some male lecturers set traps to sexually harass female students. These traps rang from awarding poor grades and faking missing marks to engineering re-takes. Other male lecturers arrange supervision appointments with female students in hotel rooms, and when the students go there, they are intimidated with low grades and raped, after which lecturers promise female students that their marks will be raised to a higher grade. Female students only shared their ordeal with their friends or leaders when the male lecturer failed to adjust the marks as promised. Those students who resist engaging in sex for marks have been punished with re-takes in the course units of those particular lecturers and have ended up not being put on the graduation list. The lecturer can continuously make the student fail and so, because some female students come from poor backgrounds, they end up dropping out of university without completing their course. KyU does not have an official system for questioning the non-completion rate of students, especially female students, although such a system would help to reveal those female students who refused to succumb to the vice of SH and so were made to retake course units or failed to get results."
\end{abstract}

A meeting with University managers confirmed the above assertion that $\mathrm{SH}$ of female students at $\mathrm{KyU}$ was exacerbated by the lack of an institutional reporting mechanism and a policy on $\mathrm{SH}$, and the inability of professional staff to handle cases of $\mathrm{SH}$.

\section{Student-to-student SH and university ecosystem}

Another form of SH was sexual relationships between students as revealed by student leaders: 
"Male students are the main perpetrators in this relationship. Male students take advantage of academically weak female students and offer to do course work or tests for them in exchange for sex. Another cause of SH was the use of alcohol or substance abuse within and around the University halls of residence and hostels of boarders. At house parties conducted by the University management to welcome new students or parties organised by the students themselves a lot of alcohol is consumed. In room parties, because of peer pressure students indulge in excessive drinking, making female students vulnerable to single or gang rape. Insecurity in and around the university due to poor lighting made some places on the campus hot spots for frequent sexual attacks, theft and physical assault, especially late in the evening, when female students have been the main victims."

Another form of SH was engineered, where a male and female student cohabit and lived like husband and wife, as revealed in the workshop.

"Many times, a female student's tuition fees and upkeep are used to pay the rent and maintain the home. When the female student gets pregnant, the male student runs away because he does not want to take the responsibility that comes with pregnancy. In most cases, female students have an abortion, lose a year of study or drop out of University."

The above assertion was confirmed at the meeting conducted with university managers, who stated that "near registration or end of semester examinations, female students are frustrated by their spouses (male students) who physically assault them and terminate the relationship, especially when the spouses (female students) get pregnant". Some students have attempted to commit suicide while others have been strangled to death.

The above views were corroborated by evidence obtained through reviewing KyU's medical centre records, which revealed 26 cases of violent sexual abuse when the victims were drunk. The records further show that from January to October 2019 the number of SH cases was high, as 37 students (17 males and 20 females) sought care from PEP services, 121 female students with unwanted pregnancies sought an abortion and there were 26 cases of rape. Female students in fear of getting pregnant received various forms of family planning, comprising oral contraceptives (41), implants (30), intrauterine devices (8) and Depo-Provera (8). Between January and September 2019, KyU Guidance and Counselling Unit received 1,908 students (731 male and 1,177 female) seeking SH-related psychological support. Further interaction with staff from the Directorate of Health Services and Guidance and Counselling Unit at KyU revealed that they were able to capture this information after probing students and ensuring confidentiality. The victims that fought back were overpowered, assaulted and raped and the perpetrators marched away without being reprimanded. As already mentioned, due to the fear of stigma, the victims just keep quiet as discussed in the next section. 


\section{Culture of silence among students and University management}

The participants indicated that students were unwilling to openly discuss $\mathrm{SH}$ issues for fear of being pursued and victimized again. Further discussions with the student leaders revealed that students with disabilities were at increased risk of being violated, but would conceal their suffering as stated below.

"Students with disabilities are bullied, ridiculed, stigmatized and sexually harassed by able-bodied students or duty bearers. Because they are unable to defend themselves, predators take advantage of their vulnerability under the cover of being kind and offering to help them. In return for their 'help' they suggest having a sexual relationship or sometimes they just rape them without their consent. Due to being unaware that rape is a crime and the stigma that comes with rape, female victims just keep quiet. They only disclose the truth to us as leaders but warn us not to report the case for fear of being doubly victimized."

During the week to Commemorate International Women's Day (March, 2020) at KyU, three concerned male lecturers and one administrative member of staff, with the permission of the victims, wanted to showcase four female students who had been sexually harassed (raped and assaulted). The victims wanted their story and experience to be heard publicly with the purpose of letting the public and management know that $\mathrm{SH}$ is widespread at KyU. All was set for the victims to give their story but they abruptly refused to do so for fear of the reprisals of the perpetrators, e.g., imposing re-takes, and because they would not be believed or protected. The victims revealed that stigma is felt personally, not collectively, and so they thought the University would not support them to receive legal redress. One of the male lecturers had this to say:

\footnotetext{
"Female students shared with me their terrifying stories of how they were raped and assaulted. We tried to pursue their cases, but the perpetrator was released on bail and he eventually bribed the police, and so the case that was filed by the police has disappeared. I mobilised these female students to take advantage of The International Women's Day (March, 2020) to air their grievances. I had video-recorded their stories with their faces blanked out with the aim of producing a programme, but although I called them every day, they refused to turn up. Their argument is that since they had not been helped by the police, the University Management might also not protect them. One of them told me that she does not want to be sacrificed to a system that does not protect them. She gave an example of a female student who was murdered by her boyfriend, which the University never followed up. She wanted to be left alone to nurse her physical and psychological wounds."
}

This study established that the culture of silence about SH and violence is not only espoused by students, but it is also deeply entrenched in university academic and administrative staff members as stated below. 
"All male and female academic participants attested that SH was rampant at the University and that victims were unwilling to report it to the legal authorities or to have it discussed at meetings of the University Council, Senate, Top Management and other forums where some members are representatives. One member laughed it off and said 'how can I be at a committee meeting and start talking about bedroom issues. You want to label me an SH Activist'?"

\section{DISCUSSION}

The study revealed that it was difficult to ascertain the extent of $\mathrm{SH}$ at $\mathrm{KyU}$ due to the in-built patriarchal institutional practices. Smith and Freyd (2014, Abstract) and Bondestam and Lindquist $(2020,402)$ demonstrated that IHL have been able to suppress details of SH because females are in subordinate positions. Bondestam and Lundqvist $(2020,406)$ showed that $\mathrm{SH}$ is not perceived as a violation of human rights, which is why it is unreported. This could have been amplified at $\mathrm{KyU}$ by the exchange value in the form of rewards, e.g., sex for marks, tuition fees, etc. Even where female students are the perpetrators, the male faculty keep silent for fear of being labelled weaklings. These findings are similar to those of Kirkner et al. $(2020,12)$, which established that 58 per cent of the professors did not report SH because they felt it was not serious or that even if they reported it nothing would be done to stop the SH pandemic.

Additionally, based on the social exchange theory and sexuality (Sprecher 1998), whereas some transactions may require the immediate exchange of goods and money, in IHL, some exchanges are premised on sex for marks or "sexually transmitted" degrees. Due to the power relations between a lecturer and a student, sex is usually transacted before the lecturer gives the student good marks as a reward. In other words, the exchange value of sex for marks is postponed (delayed reward) until the appropriate time when marks are given. The challenge comes if the lecturer is transferred or changes career, or changes are made in the system for managing examinations (setting and modulating them, central marking, recording the results and approval at department, faculty and senate level or uploading the results into the system, etc.), because this might not be a beneficial transaction, due to the delayed reward.

Time and place are also very important in sexual exchange relations. In IHL, students are only required to remain in halls of residence or hostels if they are boarders when the semester is running. Since marks are awarded after the examinations are over and sometimes when the students are on holiday, the probability of getting good marks from a lecturer for sex is slim. When sexual exchanges for marks are continuously repeated, a student's other needs might emerge (transport, eating out, hair dressing, birthday gifts, etc.), in which case the lecturer might consider exchanging sex for money for the student to spend on these things but not in exchange for good marks. This means that the student has been sexually exploited, good marks are not 
awarded and so in the end she may be made to re-take the paper or to repeat the course unit.

The foregoing demonstrates that $\mathrm{SH}$ is a pandemic in IHL, impacting individuals, groups and entire organizations in profound ways. Poor working conditions, institutional bureaucracy, normalization of SH, lack of academic integrity, a culture of silence and the lack of active leadership to address SH are all key features enabling SH in IHL. Students need to be made aware that sexual exchange for marks does not produce instant results and is not time bound, and so if they engage in sexual transactions with lecturers, they may experience negative outcomes.

Those female/male students that may be lucky in getting good marks for sex will be tested some time later. It has become common to see students with a first-class degree failing to perform on the job. The status that comes with the first-class degree does not provide the selfesteem and confidence needed to do the job.

Sexual exchanges waste time, contribute to the loss of an institution's image and, due to producing unqualified men and women, the negative impacts are felt at individual (student), household, community, national and international level. Another important dimension of this study is that a sexual exchange with a high-ranking lecturer or person in the University community does not automatically guarantee educational achievement or improved income. Instead, the lecturer uses her/his status to harass students. What needs to be made clear is that in a university, courses last for three to five years and are taught by different lecturers. A student might pass one paper but fail others because he/she did not manage to engage with some lecturers in sexual exchange for marks due to their integrity, and so that student would need to repeat a year.

Poverty was also used by students to influence sexual exchange without knowing whether it would yield optimal rewards. For example, when a university staff member or lecturer pays a student's tuition fees, will that student automatically find the sexual exchange relationship satisfying? Who has more control of such a sexual interaction, is it the student with great demand, the lecturer with little demand or is the demand reciprocal? What has also been learnt is that the social exchange theory is silent on sexual coercion. For example, a student might refuse to enter into a sexual relationship with his or her lecturer, in which case the lecturer will give him/her a low mark so that she/he has to repeat the course unit. Some sexual relations have health complications like abortions, STDs and HIV/AIDS, which not only cause students to drop out but may also have long-term effects, including death.

\section{CONCLUSION AND RECOMMENDATIONS}

This study revealed evidence of SH at KyU. The main drivers were limited awareness of SH, 
students' background of moral decadence and poverty leading them to have sexual relationships with university lecturers and a culture of silence among students and management. There is a need to embark on a programme of building a safe and positive learning environment, supported by continuous sensitization and informed by an in-depth multi-stakeholder study on the status of SH at KyU.

\section{ACKNOWLEDGEMENT}

My thanks go to all $\mathrm{KyU}$ internal and external stakeholders and $\mathrm{KyU}$ management for sharing their emotional and often painful experiences.

\section{DECLARATION OF CONFLICT OF INTEREST}

I the author of this article declare that I have no competing interests.

\section{REFERENCES}

Aguilar, S. J. and C. Baek. 2020. "Sexual harassment in academia is underreported, especially by students in the life and physical sciences." PloS one 15(3): e0230312.

Bondestam, F. and M. Lundqvist. 2020. "Sexual harassment in higher education - a systematic review." European Journal of Higher Education 10(4): 397-419.

Dogar, A. A. 2021. "Perception, Prevalence and Awareness of Sexual Harassment among University Students in Abbottabad." Psychology and Education Journal 58(1): 1182-1195.

Gillander, Gådin K. and N. Stein. 2019. "Do schools normalize sexual harassment? An analysis of a legal case regarding sexual harassment in a Swedish high school." Gender and Education 31(7): 920-937.

Harding, T. and D. Whitehead. 2013. "Analysing data in qualitative research." Nursing \& midwifery research: Methods and appraisal for evidence-based practice, 141-160.

Kirkner, A. C., K. Lorenz, and L. Mazar. 2020. "Faculty and staff reporting and disclosure of sexual harassment in higher education." Gender and Education, 1-17. DOI: 10.1080/ 09540253.2020.176392:

Lawrence, K. A and E. S. Byers. 1995. "Sexual satisfaction in long-term heterosexual relationships: The interpersonal exchange model of sexual satisfaction." Personal Relationships 2(4): 267-285.

Magaji, A. B., J. E. Ikhide, A. T. Timur, and S. Timur. 2019. "Sexual Harassment in Higher Education: Students' Perceptions and Attitudes." In Global Joint Conference on Industrial Engineering and Its Application Areas, 40-50. Springer, Cham.

Ministry of Education, Science, Technology and Sports. 2015-2020. National Strategic Plan. Elimination of Violence Against Children in Schools. Kampala.

Ministry of Education and Sports. 2012. Study on Assessing child protection, safety and security issues for children in Ugandan primary and secondary schools, 2012; Chapter 2 on study findings; section 2.3 on sexual violence. (Ministry of Education: Kampala).

MOESTS see Ministry of Education, Science, Technology and Sports.

Murray, L. K., A. Nguyen, and J. A. Cohen. 2014. Child sexual abuse. Child and Adolescent Psychiatric Clinics 23(2): 321-337.

Ondicho, N., K. Kombo, and F. Njuguna. 2019. Sexual Harassment and its Effect on Students' SelfEsteem in Selected Public and Private Secondary Schools in Kenya. Journal of Education and 
Practice 10(21): 44-53

Rusbult, C. E. 1980. "Commitment and satisfaction in romantic associations: A test of the investment model." Journal of Experimental Social Psychology 16(2): 172-186.

Rusbult, C. E.1983. "A longitudinal test of the investment model: The development (and deterioration) of satisfaction and commitment in heterosexual involvements." Journal of Personality and Social Psychology 45(1): 101-117.

Smith, C. P. and J. J. Freyd. 2014. "Institutional betrayal." American Psychologist 69(6): 575.

Sprecher, S. 1998. "Social exchange theories and sexuality." Journal of Sex Research 35(1): 32-43.

Sundaram, V. and C. Jackson. 2018. "'Monstrous men' and 'sex scandals': The myth of exceptional deviance in sexual harassment and violence in education." Palgrave Communications 4(1): 1-5.

UNICEF. 2015. Ending Child Marriage and Teenage Pregnancy in Uganda: A Formative Research to Guide the Implementation of the National Strategy on Ending Child Marriage and Teenage Pregnancy in Uganda. Final Report, Uganda.

Walster, E., G. W. Walster, and E. Berscheid. 1978. Equity: Theory and Research, Boston: Allyn and Bacon. 